\title{
ANL/EDKCP -84984
}

CONF-9505251--1

\section{MODERATOR/COLLIMATOR FOR A PROTON/DEUTERON LINAC TO PRODUCE A HIGH-INTENSITY, HIGH-QUALITY THERMAL NEUTRON BEAM FOR NEUTRON RADIOGRAPHY}

by

R.C. Singleterry Jr., G.R. Imel*, and G.E. McMichael**

JUN 191995

*Argonne National Laboratory, P.O. Box 2528, Idaho Falls, ID 83403-2528 USQ S T I

**Argonne National Laboratory, 9700 South Cass Ave., TD/207, Argonne, IL 60439 USA

1995 Particle Accelerator Conference and International Conference on High-Energy Accelerators

Hyatt Regency Hotel, Dallas, Texas

$$
\text { May } 1^{\text {st }}-5^{\text {th }}, 1995
$$

The submitted manuscript has been authored by a contractor of the U.S. Government under contract No. W-31-109-ENG-38 Accordingly, the U.S. Government retains a nonexclusive, royalty-free license to publish or reproduce the published form of this contribution, or allow others to do so, for U.S. Government purposes.

\section{DISCLAIMER}

This report was prepared as an account of work sponsored by an agency of the United States Government. Neither the United States Government nor any agency thereof, nor any of their employees, makes any warranty, express or implied, or assumes any legal liability or responsibility for the accuracy, completeness, or usefulness of any information, apparatus, product, or process disclosed, or represents that its use would not infringe privately owned rights. Reference herein to any specific commercial product, process, or service by trade name, trademark, manufacturer, or otherwise does not necessarily constitute or imply its endorsement, recommendation, or favoring by the United States Government or any agency thereof. The views and opinions of authors expressed herein do not necessarily state or reflect those of the United States Government or any agency thereof. 


\title{
MODERATOR/COLLIMATOR FOR A PROTON/DEUTERON LINAC TO PRODUCE A HIGH-INTENSITY, HIGH-QUALITY THERMAL NEUTRON BEAM FOR NEUTRON RADIOGRAPHY
}

\author{
R.C. Singleterry Jr., G.R. Imel ${ }^{*}$, and G.E. McMichael** \\ *Argonne National Laboratory, P.O. Box 2528, Idaho Falls, ID 83403-2528 USA \\ **Argonne National Laboratory, 9700 South Cass Ave., TD/207, Argonne, IL 60439 USA
}

\section{Abstract}

Reactor based high resolution neutron radiography facilities are able to deliver a well-collimated ( $\mathrm{L} / \mathrm{D} \geq 100)$ thermal flux of $10^{6} \mathrm{n} / \mathrm{cm}^{2} \cdot \mathrm{sec}$ to an image plane. This is well in excess of that achievable with the present accelerator based systems such as sealed tube D-T sources, Van der Graafe s s stall cyclotrons, or low duty factor linacs. However, continuous wave linacs can accelerate tens of milliamperes of protons to 2.5 to $4 \mathrm{MeV}$. The MCNP code has been used to analyze target/moderator configurations that could be used with Argonne's Continuous Wave Linac (ACWL). These analyses have shown that ACWL could be modified to generate a neutron beam that has a high intensity and is of high quality.

\section{INTRODUCTION}

Neutron Radiography (NR) has been the domain of thermal reactors until the present day. The reactor was the easiest and most economical method for the generation of a high quality, high intensity thermal neutron source. Today, reactors are becoming expensive to license and operate and are not portable. At the same time, charged particle accelerator technology is advancing, intensities are increasing, and hardware is decreasing in size. This paper investigates the use of a charged particle accelerator, the Argonne Continuous Wave Linac (ACWL) at Argonne National Laboratory in Illinois, to generate a high quality, high intensity thermal flux suitable for NR.

\section{ACCELERATOR FACILITY}

The original purpose of ACWL was as an accelerator development test stand for the Strategic Defense Initiative (SDI) as describe in Reference [1]. This mission has ended, so ACWL is being modified to investigate the use of accelerators in NR and Boron Neutron Capture Therapy with the current work concentrating on NR. ACWL was designed and built to accelerate negative deuteron ions in a radio frequency quadrupole accelerator in a Drift Tube Linac (DTF). The facility is being modified for water cooling versus the more expensive cryogenic cooling needed for the space environment of the SDI mission. If it is deemed that proton acceleration is needed, the particle generation equipment exists and can be fitted to ACWL readily. This analysis investigates what particle(s), particle energies, and particle currents are needed to perform NR with the intended goals.

\section{NEUTRONIC ANALYSES}

Various models of the new ACWL target facility were analyzed for neutronic properties with the MCNP code and ENDF/B-V continuous energy cross sections. The MCNP code system simulates many particle trajectories using a stochastic method. With these tools, analyses were performed to determine if ACWL with a suitable target could generate the beam needed to obtain the goals. The first step was to generate a source definition that modeled the neutron generation reactions. The target area and thickness were chosen to enable the target to dissipate the heat generated by the reaction. A moderator substance and configuration were designed to generate as many thermal neutrons as possible without contaminating the beam with gammas and higher energy neutrons. The beam tube was designed to transport those neutrons to the image plane and maintain its high resolution capability.

\section{A. Source Model for the $L i^{7}$-proton Reaction}

Since MCNP cannot analyze charged particles other than electrons, the model for the source was performed separately. The reaction of interest was the $\mathrm{Li}^{7}(\mathrm{p}, \mathrm{n}) \mathrm{Be}^{7}$ reaction. Experimentally based cross section data was given in Reference [2]. The resultant energy and direction of the outgoing neutron was calculated from the two-body equations as formulated in Reference [3]. Figure 1 shows the neutron source strength as a function of proton energy and laboratory angle. Continuous slowing down theory was used to model the protons while traveling through the target. Reference [4] was used for the stopping power of hydrogen ions in the target materials.

The neutron source strength was collapsed into a source definition recognized by MCNP. To do this, the angular variable was broken into evenly distributed angle bins from 0 to 180 degrees with the probability equal to the normalized source strength. To link the angular distribution to the neutron energy distribution for that angle, the dependant source mechanism in MCNP was used. Each angle bin was made dependant to an energy range and probability as shown in Figure 2. The energy range is the maximum and minimum energies shown in Figure 2 for each angle, while the probability distribution was set equal to the normalized source strength for that angle.

\section{B. Target Design}

Exact details of the target design are not necessary for this analysis. The materials that could scatter or absorb 


\section{DISCLAIMER}

Portions of this document may be illegible in electronic image products. Images are produced from the best available original document. 


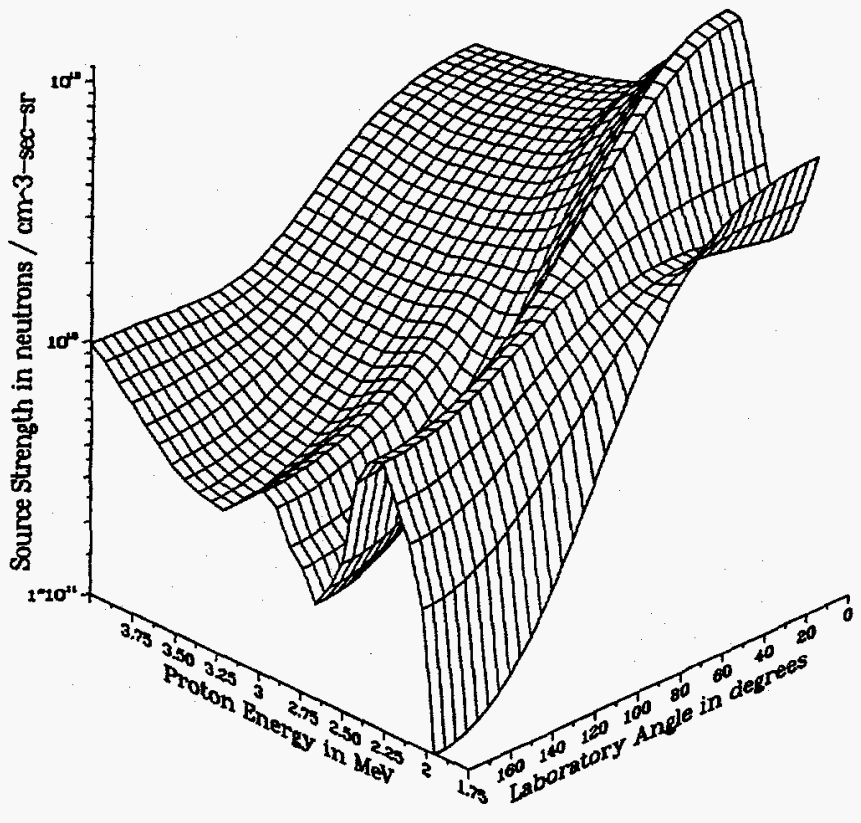

Figure. 1. The Neutron Source Strength as a Function of Laboratory System Angle and Proton Energy in Lithium

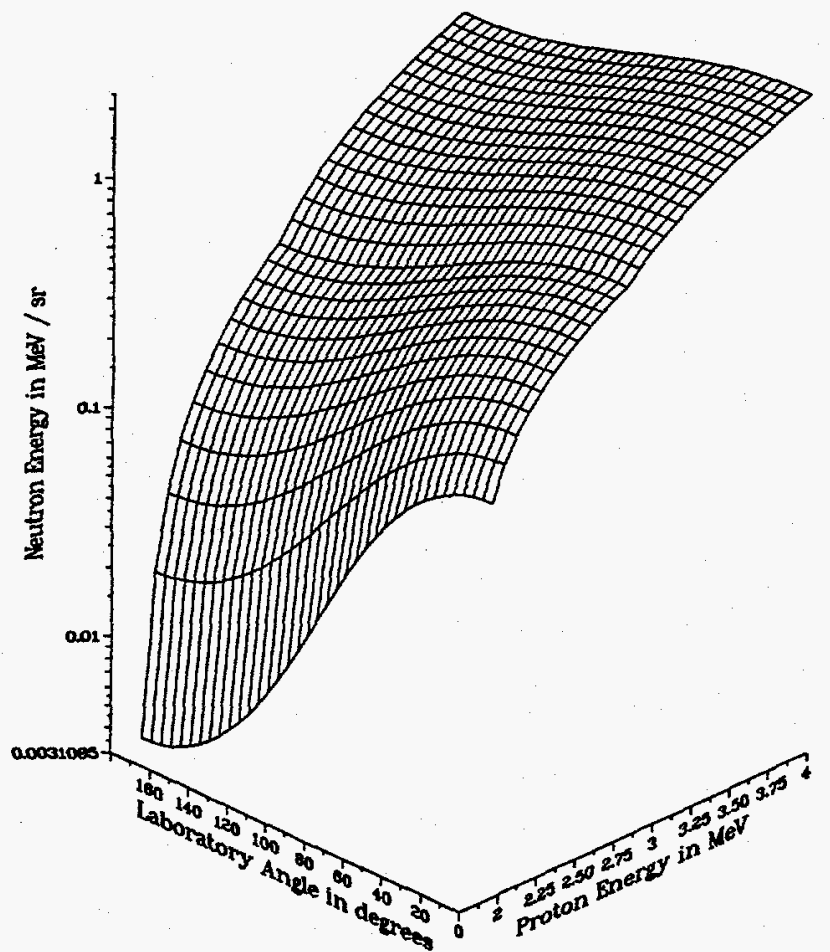

Figure. 2. The Neutron Energy Distribution as a Function of Laboratory System Angle and Proton Energy in Lithium neutrons and their position are the important details modeled. The proton target is modeled as a right circular cylinder which projects enough circular surface area to the proton beam so it absorbs approximately $1 \frac{\mathrm{kW}}{\mathrm{cm}^{2}}$ of energy. The proton target is attached to a copper plate and sealed in a stainless steel 316 evacuated can that extends to the left hand edge of the model. The can is slightly larger than the proton beam to allow clear passage of the beam to the target.

\section{Moderator and Reflector Design}

The neutron energies from the source are between $2.5 \mathrm{MeV}$ and $0.002 \mathrm{MeV}$. The goal is to have a large number of neutrons enter the beam tube with a mean energy of $0.0253 \mathrm{eV}$ (thermal neutrons). The moderator must slow the neutrons down to these energies without absorbing the neutrons, spreading them through geometry effects, or having them escape. A low atomic weight, high density moderator is used to achieve the largest energy loss per collision possible to keep the geometry losses to a minimum. A reflector material is placed outside of the moderator to economize on neutrons.

The neutron source is very forward peaked. Tally surfaces were placed in the model to cover possible positions for apertures. To accelerate the MCNP calculation, gamma rays were not simulated in the models to determine placement of the aperture; however, in the final model, gamma rays were included.

\section{Beam Tube Design}

The objective is to obtain a collimated beam of neutrons having a thermal flux of $10^{6}$ neutrons per $\mathrm{cm}^{2}$ sec striking the image plane with an image quality category of I as described in Reference [5]. A first order approximation for the flux entering the beam tube is

$$
\phi_{0}=16 \phi_{I}\left(\frac{L}{D}\right)^{2},
$$

where, $\phi_{I}$ is the flux at the image plane $\left(10^{6}\right), L$ is the length of the beam tube, and $D$ is the diameter of the aperture.

In order to achieve the goal of a high quality beam, an $\mathrm{L} / \mathrm{D}$ of 100 is needed. From equation (1), this gives an attenuation of $1.6 \times 10^{5}$, or to achieve a flux of $10^{6}$, the flux at the aperture must be $1.6 \times 10^{11}$ neutrons per $\mathrm{cm}^{2} \cdot \mathrm{sec}$. To absorb any stray or reflecting neutrons from or through the beam tube, a stainless steel can is lined with a thin layer of cadmium or other large cross section material (see Reference [6]). This lining keeps neutrons from entering or exiting the beam tube except at the aperture and the image and preserves the collimation of the beam.

\section{RESULTS}

The results reported here are for a $2.5 \mathrm{MeV}$ and a $4.0 \mathrm{MeV}$ proton beam impinging on a lithium target with light and heavy water as the moderator and graphite as the reflector. The lithium target is $5 \mathrm{~cm}$ in radius and $0.1 \mathrm{~cm}$ 


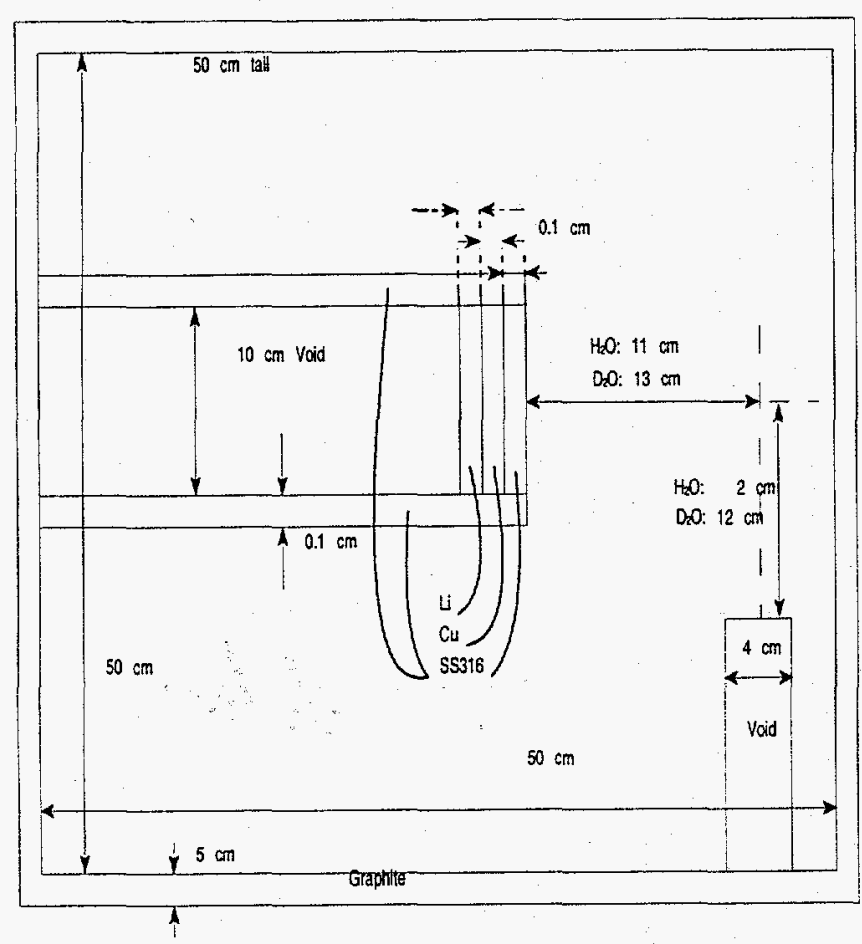

Figure. 3. Geometric Representation of the Physical Model

Table I

Thermal to Total Neutron Flux and Optimal Position

\begin{tabular}{|l|l|c|c|c|}
\hline $\begin{array}{l}\text { Proton } \\
\text { Energy } \\
\mathrm{MeV}\end{array}$ & $\begin{array}{l}\text { Slowing } \\
\text { Down } \\
\text { Material }\end{array}$ & $\frac{\phi_{t h}}{\phi}$ & $\begin{array}{c}\text { Source } \\
\text { Distance } \\
\text { cm }\end{array}$ & $\begin{array}{c}\text { Direction } \\
\text { from Beam } \\
\text { degrees }\end{array}$ \\
\hline 2.5 & $\mathrm{H}_{2} \mathrm{O}$ & 0.319718 & 11 & 90 \\
\hline 4.0 & $\mathrm{H}_{2} \mathrm{O}$ & 0.308378 & 11 & 90 \\
\hline 2.5 & $\mathrm{D}_{2} \mathrm{O}$ & 0.012559 & 13 & 90 \\
\hline 4.0 & $\mathrm{D}_{2} \mathrm{O}$ & 0.012235 & 13 & 90 \\
\hline
\end{tabular}

thick and is placed at the center of a water box $50 \mathrm{~cm}$ on a side. A $5 \mathrm{~cm}$ thick graphite reflector was employed outside of the box. To keep the perturbation from the aperture small, the diameter was set to $4 \mathrm{~cm}$. Figure 3 gives a representation of the geometry. The results from these models create a working set of parameters for determination of the feasibility of this effort. From this, a complete study of materials and configurations can be completed to design the actual target to be employed at ACWL.

Table I shows the ratio of the thermal to the total neutron flux at the optimum position without the beam tube modeled. Table II shows the thermal neutrons per source neutron at the beam tube entrance (location given in Table I) and the proton current needed to achieve the objective of $10^{6} \mathrm{n} / \mathrm{cm} 2 \cdot \mathrm{sec}$ of the assumed image plane.
Table II

Thermal Neutrons per Source Neutron and Proton Current for High Intensity NR

\begin{tabular}{|l|l|c|c|}
\hline $\begin{array}{l}\text { Proton } \\
\text { Energy } \\
\mathrm{MeV}\end{array}$ & $\begin{array}{l}\text { Slowing } \\
\text { Down } \\
\text { Material }\end{array}$ & $\begin{array}{c}\text { Thermal } \\
\text { Neutrons } \\
\mathrm{n} / \text { Source } \mathrm{n}\end{array}$ & $\begin{array}{c}\text { Proton } \\
\text { Current } \\
\mathrm{mA}\end{array}$ \\
\hline 2.5 & $\mathrm{H}_{2} \mathrm{O}$ & $5.45353 \mathrm{E}-6$ & 59.1 \\
\hline 4.0 & $\mathrm{H}_{2} \mathrm{O}$ & $4.66151 \mathrm{E}-6$ & 69.1 \\
\hline 2.5 & $\mathrm{D}_{2} \mathrm{O}$ & - & - \\
\hline 4.0 & $\mathrm{D}_{2} \mathrm{O}$ & - & - \\
\hline
\end{tabular}

\section{CONCLUSION}

With the MCNP code, it is possible to model the entire system. The problem that is encountered is the creation of a biasing scheme to cut the number of simulated particles needed to converge the model. The simplifications made in this model allowed short ( 6 to $20 \mathrm{CPU}$ hours on a Sun Sparc 20) turn-around times but in no way encompassed all parameters needed to design a target and beam tube for high intensity and high quality NR. However, this study did determine that NR is feasible with light water at ACWL and showed approximate results that could be obtained. The next step is to investigate more moderating materials such as polyethylene and optimize the placement of the beam aperture. Once this work is finished, the design and construction of a target and beam tube for ACWL to assist in the research needed for portable NR devices can continue.

\section{References}

[1] McMichael, G., et. al.; CWDD Accelerator at Argonne - Status and Future Opportunities; Proceedings of the 1994 LINAC Conference; Tsukuba Japan, August 21-26, 1994, page 131.

[2] Liskien, Horst and Paulsen, Arno; Neutron Production Cross Sections and Energies for the Reactions ${ }^{7} \mathrm{Li}(p, n)^{7} \mathrm{Be}$ and ${ }^{7} \mathrm{Li}(p, n)^{7} \mathrm{Be}$; Atomic Data and Nuclear Data Tables, 15, 57-84 (1975).

[3] Lamarsh, John R.; Introduction to Nuclear Reactor Theory, Addison-Wesley Publishing Company, (1966).

[4] Andersen, H.H. and Ziegler, J.F.; Hydrogen, Stopping Powers and Ranges in All Elements; Volume 3 of The Stopping and Ranges of Ions in Matter; Pergamon Press (1977).

[5] Standard Method for Determining Image Quality in Direct Thermal Neutron Radiographic Examination, Vol. 03.03 Nondestructive Testing, ASTM E 545-91, (1994).

[6] Von Der Hardt, P. and Röttger, H., Editors; Neutron Radiography Handbook; Commission of the European Communities; D. Reidel Publishing Company (1981). 